\title{
Statins for aneurysmal subarachnoid haemorrhage: Another loss in translation
}

\author{
Matthew T. V. Chan
}

\begin{abstract}
Experimental evidence suggests that statin attenuates inflammation, oxidation, platelet aggregation and excitotoxicity. In brain ischemic models, statin administration produces vasodilatation and reduces neuronal apoptosis. It was hypothesized that statin administration may improve outcome by reducing delayed ischemic neurological deficit after aneurysmal subarachnoid haemorrhage. Earlier pilot trials suggested demonstrated encouraging results but the recent Simvastatin in Aneurysmal Subarachnoid Haemorrhage Trial, using simvastatin $40 \mathrm{mg}$ per day, failed to demonstrate a benefit. Even at larger doses, simvastatin $80 \mathrm{mg}$ per day did not reduce delayed ischemic neurological deficit. In common with many other interventions, statin represents another translational failure of presumed neuroprotective agents.
\end{abstract}

Key words: Aneurysmal subarachnoid haemorrhage, delayed ischaemic neurological deficit, statin

\section{INTRODUCTION}

Aneurysmal subarachnoid haemorrhage affects $2-22 / 100,000$ persons every year and is associated with high morbidity and mortality rate. ${ }^{[1,2]}$ The reported 30-day case fatality rate was between $32 \%$ and $42 \% \cdot{ }^{[3,4]}$ Among patients who survived the initial insult, $30 \%-50 \%$ of patients were severely disabled and required life-long assistance. ${ }^{[1-4]}$ Early mortality of aneurysmal subarachnoid haemorrhage is due to re-bleeding, intracranial hypertension and cerebral oedema. Subsequent causes of death are related to sepsis, pulmonary aspiration, metabolic derangement, myocardial infarction, heart failure and thromboembolism. ${ }^{[2,5]}$ In addition, a substantial proportion $(18 \%-56 \%)$ of patients suffers secondary

Department of Anaesthesia and Intensive Care,

The Chinese University of Hong Kong,

Hong Kong SAR, China

Address for correspondence:

Dr. Matthew T. V. Chan, Department of Anaesthesia and

Intensive Care, The Chinese University of Hong Kong, Shatin,

New Territories, Hong Kong SAR, China.

E-mail: mtvchan@cuhk.edu.hk

\begin{tabular}{|l|l|}
\hline \multicolumn{2}{|c|}{ Access this article online } \\
\hline Quick Response Code: & Website: \\
\hline & www.jnaccjournal.org \\
\cline { 2 - 2 } & \\
\hline
\end{tabular}

ischaemia, 3-10 days after aneurysmal subarachnoid haemorrhage. Delayed ischaemic neurological deficit due to cerebral vasospasm is currently considered as an important cause of poor outcome after subarachnoid haemorrhage. ${ }^{[6,7]}$

Biologically, the presence of deoxy (ferrous)-haemoglobin in the basal subarachnoid space and the initial insult from early cerebral hypoxia and ischaemia trigger a wide range of damages. These include release of oxygen free radicals, depletion of nitric oxide in the endothelium and initiation of spreading depression [Figure 1]. ${ }^{[5-9]}$ Each of these processes contributes to spasm and thrombosis in the microcirculation and may result in delayed ischaemic neurological deficits.

\section{STATINS TO IMPROVE NEUROLOGICAL OUTCOME AFTER SUBARACHNOID HAEMORRHAGE}

Statins are competitive inhibitors of 3-hydroxy-3-methylglutaryl coenzyme A reductase,

This is an open access article distributed under the terms of the Creative Commons Attribution-NonCommercial-ShareAlike 3.0 License, which allows others to remix, tweak, and build upon the work non-commercially, as long as the author is credited and the new creations are licensed under the identical terms.

For reprints contact: reprints@medknow.com

How to cite this article: Chan MT. Statins for aneurysmal subarachnoid haemorrhage: Another loss in translation. J Neuroanaesthesiol Crit Care 2017;4:S60-4. 
a rate-limiting enzyme of the mevalonate pathway, which is pivotal for the production of cholesterol and mevalonate. Experimentally, statins produce a number of cholesterol-independent effects. ${ }^{[9]}$ These include as follows:

- Anti-inflammation ${ }^{[10,11]}$ - Stain inhibits intracellular cholesterol synthesis such that neuro-inflammation is attenuated after focal cerebral ischaemia. This is dependent on CD11b expression and inhibition of monocyte adhesion to endothelium ${ }^{[12]}$

- Anti-oxidation - This is a dose-dependent effect primarily due to a decrease in oxidase activity and suppression of free oxygen radical production ${ }^{[13]}$

- Anti-platelet - There is a direct inhibitory effect on platelet. In addition, there is a decrease in platelet response to thrombin and platelet disposition to the exposed and damaged endothelium ${ }^{[14]}$

- Anti-excitotoxicity ${ }^{[15]}$ - This is associated with $\mathrm{N}$-methyl-d-aspartate receptor antagonism and a decrease in calcium influx with glutamate stimulation

- Anti-apoptosis - Statins are known to inhibit caspase 3-dependent apoptotic pathway and thus reduce neuronal apoptosis. Statins have also been shown to induce neurogenesis and synaptogenesis after ischaemic brain injury ${ }^{[16]}$

- Vasodilatation ${ }^{[17]}$ - Statin inhibits Rho GTPase and activates protein kinase B. The end result is an increase in endothelial-derived nitric oxide synthase activity, resulting in cerebral vasodilatation and restoration of auto-regulation.

These effects, working individually or in combination, may exert neuro-protection to subarachnoid haemorrhage by limiting neuronal damage during initial impact and prevent subsequent vasospasm [Figure 1]. It should

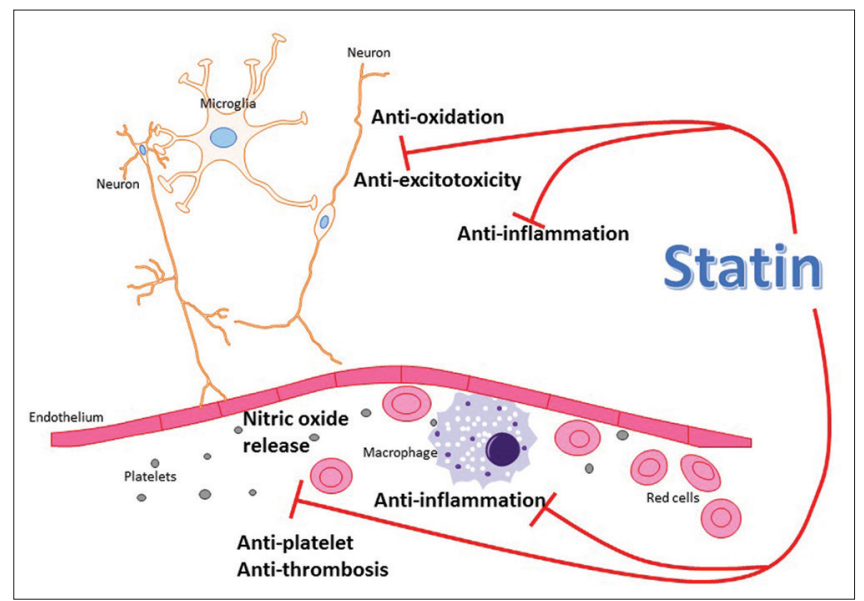

Figure 1: Mechanisms of statin-induced neuro-protection. In the blood stream, statin prevents macrophage adhesion, increases nitric oxide bioavailability, reduces thrombus formation and promotes endothelial vasomotor function. In the brain side, statin possesses antioxidant properties and suppresses cytokine responses during cerebral ischaemia be noted that only simvastatin and lovastatin cross the blood-brain barrier, ${ }^{[18]}$ and the current research has focussed on the use of simvastatin to improve neurological outcome after aneurysmal subarachnoid haemorrhage.

In experimental models, simvastatin treatment before and after subarachnoid haemorrhage attenuated cerebral vasospasm and significantly improved neurological outcomes. ${ }^{[16,19-21]}$ Similarly, in a meta-analysis of animal stroke models, treatment with simvastatin decreases infarct volume by $25 \%-30 \%$ and improves neurological outcome scores by $20 \%$. $^{[22]}$

Given these encouraging results, a few pilot trials have been performed to test the feasibility of large randomised trial. ${ }^{[20,23-27]}$ Figures 2 and 3 show the pooled effect of high-dose simvastatin, $80 \mathrm{mg} /$ day, given for 14-21 days after subarachnoid haemorrhage. Compared with placebo, the rates of delayed ischaemic deficit tended to be lower with simvastatin treatment $(40.3 \%$ vs. $54.7 \%),{ }^{[23,24,26,27]}$ odds ratio (95\% confidence intervals): $0.54(0.27-1.08), P=0.083$. More importantly, simvastatin treatment was well tolerated. Neurological recovery was not improved. The odds ratio $(95 \%$ confidence intervals for unfavourable neurological outcome at 6 months after subarachnoid hemorrahge 1.18 (0.90-1.55).

\section{SIMVASTATIN IN ANEURYSMAL SUBARACHNOID HAEMORRHAGE TRIAL}

Based on the potential benefits of simvastatin highlighted in pilot trials, an international randomised controlled trial was conducted. The simvastatin in aneurysmal subarachnoid haemorrhage (STASH) trial randomised 803 patients presented within $96 \mathrm{~h}$ from onset of symptoms to receive either simvastatin $40 \mathrm{mg}$ or matched placebo tablets for 3 weeks. ${ }^{[28]}$ The primary end-point was functional performance measured by

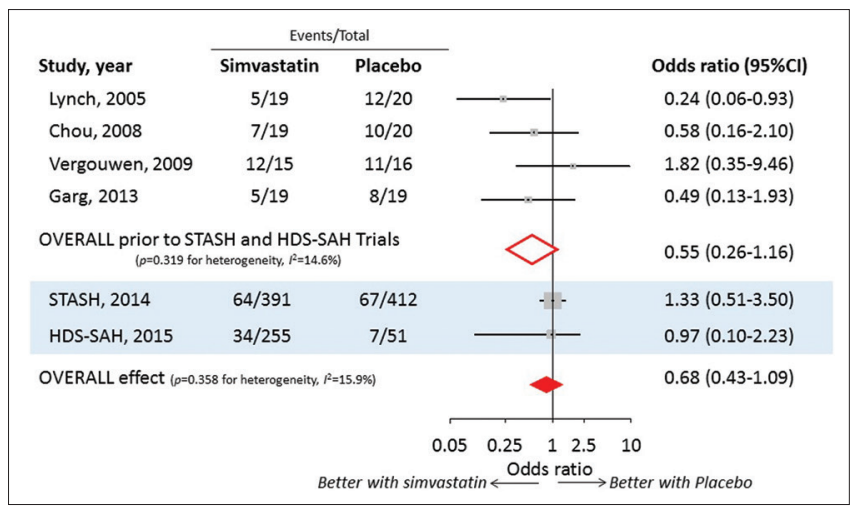

Figure 2: Forrest plot of odds ratios to measure the effect of simvastatin on the prevention of delayed neurological ischaemic deficit before and after reporting of the simvastatin in aneurysmal subarachnoid haemorrhage trial and high-dose simvastatin for aneurysmal subarachnoid haemorrhage trial 
the modified Rankin scale score at 6 months after randomisation. Throughout the study, the rate of cerebral vasospasm was similar (simvastatin $16 \%$ vs. placebo 16\%). At 6 months after randomisation, there was no difference in neurological recovery (modified Rankin score scale $\leq 2$ : Simvastatin $72 \%$ vs. placebo $72 \%)$ between groups. These findings suggest that simvastatin $40 \mathrm{mg} /$ day had no measurable effect of neurological recovery after aneurysmal subarachnoid haemorrhage.

It should be noted that STASH trial used lower dose than previous trials and may have led to limited efficacy. In this respect, simvastatin $80 \mathrm{mg} /$ day is the largest dose approved clinically. It is therefore unclear whether high-dose regimen (simvastatin $80 \mathrm{mg} /$ day) would produce superior neurological recovery compared with the lower dose (simvastatin $40 \mathrm{mg} /$ day).

\section{HIGH-DOSE SIMVASTATIN FOR ANEURYSMAL SUBARACHNOID HAEMORRHAGE TRIAL}

We have recently reported the high-dose simvastatin for aneurysmal subarachnoid haemorrhage (HDS-SAH) trial. ${ }^{[29]}$ A total of 255 patients who presented within $96 \mathrm{~h}$ of aneurysmal subarachnoid haemorrhage were randomised to receive simvastatin 80 or $40 \mathrm{mg} /$ day for 21 days. Delayed ischaemic deficit was recorded as the primary outcome and neurological recovery at 3 months after subarachnoid haemorrhage was the secondary end-point.

In the HDS-SAH trial, there was no difference in the rate of delayed ischaemic neurological deficit between groups (simvastatin $80 \mathrm{mg}-27 \%$ vs. simvastatin $40 \mathrm{mg}-32 \%$ ). Neurological recovery was also similar between groups. When compared with another cohort of patients who have not been exposed to simvastatin treatment $(n=51)$, neurological recovery or delayed ischaemic neurological deficit was similar to patients receiving simvastatin treatment. The findings were not changed substantially after adjustment for severity of subarachnoid haemorrhage, gender, age and location of aneurysm. ${ }^{[30]}$ Cognitive performance also did not differ between groups.

\section{CONCLUSIONS}

The current data suggest that simvastatin, regardless of dose regimens, given after subarachnoid haemorrhage does not affect the rate of delayed ischaemic neurological deficit or functional neurological recovery. Similar to many other agents, such as magnesium ${ }^{[31-33]}$ and clazosentan, ${ }^{[34-36]}$ statin fails to translate laboratory results to clinical success. This is not surprising given the
Table 1: Important differences between animal and human research

Heterogeneity in subjects
Comorbidity
Age (older in human research vs. younger animals in
laboratory research)
Animal model does not represent human disease
Severity in subarachnoid haemorrhage
Differences in aetiology
Treatment window - delayed treatment in human
research
Endpoint differences
Infarct volume, surrogate markers in animal research
versus neurological (functional) recovery in human trials

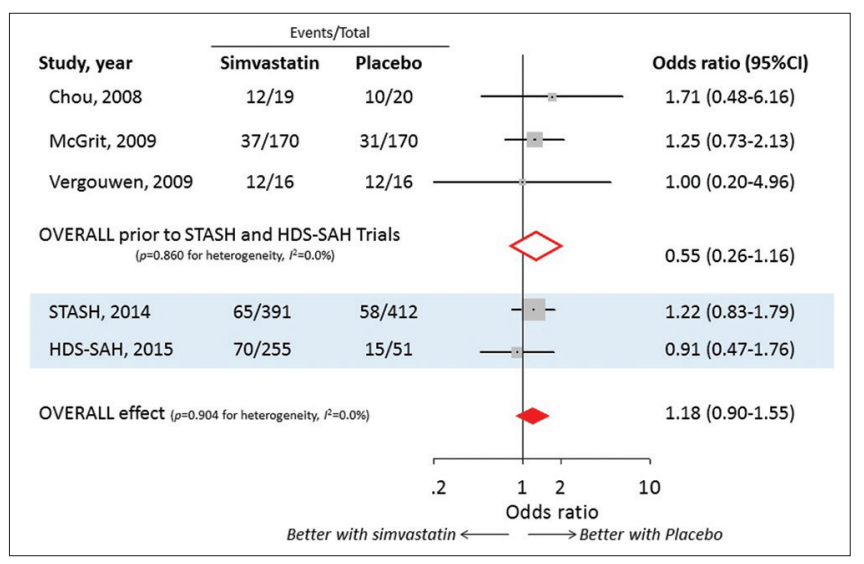

Figure 3: Forrest plot of odds ratios to measure the impact of simvastatin on the unfavourable neurological outcome before and after reporting of the simvastatin in aneurysmal subarachnoid haemorrhage trial and high-dose simvastatin for aneurysmal subarachnoid haemorrhage trial

heterogeneity of aneurysmal subarachnoid haemorrhage in humans compares with purposely designed animal models. There are also issues of treatment time window when a delay of $96 \mathrm{~h}$ may be too long in humans [Table 1]. More importantly, the current literature shows that results from small clinical trials are generally fragile and that adequately powered trial will be required to inform clinical care. ${ }^{[37]}$

\section{Financial support and sponsorship Nil.}

\section{Conflicts of interest}

There are no conflicts of interest.

\section{REFERENCES}

1. Suarez JI, Tarr RW, Selman WR. Aneurysmal subarachnoid hemorrhage. N Engl J Med 2006;354:387-96.

2. D'Souza S. Aneurysmal subarachnoid hemorrhage. 
J Neurosurg Anesthesiol 2015;27:222-40.

3. Koffijberg H, Buskens E, Granath F, Adami J, Ekbom A, Rinkel GJ, et al. Subarachnoid haemorrhage in Sweden 1987-2002: Regional incidence and case fatality rates. J Neurol Neurosurg Psychiatry 2008;79:294-9.

4. Ingall $\mathrm{T}$, Asplund $\mathrm{K}$, Mähönen $\mathrm{M}$, Bonita R. A multinational comparison of subarachnoid hemorrhage epidemiology in the WHO MONICA stroke study. Stroke 2000;31:1054-61.

5. Chen S, Feng H, Sherchan P, Klebe D, Zhao G, Sun X, et al. Controversies and evolving new mechanisms in subarachnoid hemorrhage. Prog Neurobiol 2014;115:64-91.

6. Abla AA, Wilson DA, Williamson RW, Nakaji P, McDougall CG, Zabramski JM, et al. The relationship between ruptured aneurysm location, subarachnoid hemorrhage clot thickness, and incidence of radiographic or symptomatic vasospasm in patients enrolled in a prospective randomized controlled trial. J Neurosurg 2014;120:391-7.

7. Knuckey NW, Fox RA, Surveyor I, Stokes BA. Early cerebral blood flow and computerized tomography in predicting ischemia after cerebral aneurysm rupture. J Neurosurg 1985;62:850-5.

8. Shimamura N, Ohkuma $\mathrm{H}$. Phenotypic transformation of smooth muscle in vasospasm after aneurysmal subarachnoid hemorrhage. Transl Stroke Res 2014;5:357-64.

9. Pluta RM, Hansen-Schwartz J, Dreier J, Vajkoczy P, Macdonald RL, Nishizawa S, et al. Cerebral vasospasm following subarachnoid hemorrhage: Time for a new world of thought. Neurol Res 2009;31:151-8.

10. Ferns GA. Differential effects of statins on serum CRP levels: Implications of recent clinical trials. Atherosclerosis 2003;169:349-51.

11. Ridker PM. Inflammatory biomarkers, statins, and the risk of stroke: Cracking a clinical conundrum. Circulation 2002;105:2583-5.

12. Weber C, Erl W, Weber KS, Weber PC. HMG-CoA reductase inhibitors decrease CD11b expression and CD11b-dependent adhesion of monocytes to endothelium and reduce increased adhesiveness of monocytes isolated from patients with hypercholesterolemia. J Am Coll Cardiol 1997;30:1212-7.

13. Human JA, Ubbink JB, Jerling JJ, Delport R, Vermaak WJ, Vorster $\mathrm{HH}$, et al. The effect of simvastatin on the plasma antioxidant concentrations in patients with hypercholesterolaemia. Clin Chim Acta 1997;263:67-77.

14. Huhle G, Abletshauser C, Mayer N, Weidinger G, Harenberg J, Heene DL. Reduction of platelet activity markers in type II hypercholesterolemic patients by a HMG-CoA-reductase inhibitor. Thromb Res 1999;95:229-34.

15. Zacco A, Togo J, Spence K, Ellis A, Lloyd D, Furlong S, et al. 3-hydroxy-3-methylglutaryl coenzyme a reductase inhibitors protect cortical neurons from excitotoxicity. J Neurosci 2003;23:11104-11.

16. Chen J, Zhang ZG, Li Y, Wang Y, Wang L, Jiang H, et al. Statins induce angiogenesis, neurogenesis, and synaptogenesis after stroke. Ann Neurol 2003;53:743-51.

17. Delanty N, Vaughan CJ. Vascular effects of statins in stroke. Stroke 1997;28:2315-20.

18. Saheki A, Terasaki T, Tamai I, Tsuji A. In vivo and in vitro blood-brain barrier transport of 3-hydroxy-3-methylglutaryl coenzyme A (HMG-CoA) reductase inhibitors. Pharm Res 1994;11:305-11.

19. Sugawara T, Ayer R, Jadhav V, Chen W, Tsubokawa T, Zhang JH. Simvastatin attenuation of cerebral vasospasm after subarachnoid hemorrhage in rats via increased phosphorylation of akt and endothelial nitric oxide synthase. J Neurosci Res 2008;86:3635-43.

20. McGirt MJ, Blessing R, Alexander MJ, Nimjee SM, Woodworth GF, Friedman AH, et al. Risk of cerebral vasopasm after subarachnoid hemorrhage reduced by statin therapy: A multivariate analysis of an institutional experience. J Neurosurg 2006;105:671-4.

21. Chen J, Cui X, Zacharek A, Chopp M. Increasing Ang1/Tie2 expression by simvastatin treatment induces vascular stabilization and neuroblast migration after stroke. J Cell Mol Med 2009;13:1348-57.

22. García-Bonilla L, Campos M, Giralt D, Salat D, Chacón P, Hernández-Guillamon $\mathrm{M}$, et al. Evidence for the efficacy of statins in animal stroke models: A meta-analysis. J Neurochem 2012;122:233-43.

23. Garg K, Sinha S, Kale SS, Chandra PS, Suri A, Singh MM, et al. Role of simvastatin in prevention of vasospasm and improving functional outcome after aneurysmal sub-arachnoid hemorrhage: A prospective, randomized, double-blind, placebo-controlled pilot trial. Br J Neurosurg 2013;27:181-6.

24. Chou SH, Smith EE, Badjatia N, Nogueira RG, Sims JR $2^{\text {nd }}$, Ogilvy CS, et al. A randomized, double-blind, placebo-controlled pilot study of simvastatin in aneurysmal subarachnoid hemorrhage. Stroke 2008;39:2891-3.

25. McGirt MJ, Garces Ambrossi GL, Huang J, Tamargo RJ. Simvastatin for the prevention of symptomatic cerebral vasospasm following aneurysmal subarachnoid hemorrhage: A single-institution prospective cohort study. J Neurosurg 2009;110:968-74.

26. Lynch JR, Wang H, McGirt MJ, Floyd J, Friedman AH, Coon AL, et al. Simvastatin reduces vasospasm after aneurysmal subarachnoid hemorrhage: Results of a pilot randomized clinical trial. Stroke 2005;36:2024-6.

27. Vergouwen MD, Meijers JC, Geskus RB, Coert BA, Horn J, Stroes ES, et al. Biologic effects of simvastatin in patients with aneurysmal subarachnoid hemorrhage: A double-blind, placebo-controlled randomized trial. J Cereb Blood Flow Metab 2009;29:1444-53.

28. Kirkpatrick PJ, Turner CL, Smith C, Hutchinson PJ, Murray GD; STASH Collaborators. Simvastatin in aneurysmal subarachnoid haemorrhage (STASH): A multicentre randomised phase 3 trial. Lancet Neurol 2014;13:666-75.

29. Wong GK, Chan DY, Siu DY, Zee BC, Poon WS, Chan MT, et al. High-dose simvastatin for aneurysmal subarachnoid hemorrhage: Multicenter randomized controlled double-blinded clinical trial. Stroke 2015;46:382-8.

30. Wong GK, Wong A, Zee BC, Poon WS, Chan MT, Gin T, et al. Cognitive outcome in acute simvastatin treatment for aneurysmal subarachnoid hemorrhage: A propensity matched analysis. J Neurol Sci 2015;358:58-61.

31. Wong GK, Poon WS, Chan MT, Boet R, Gin T, Ng SC, et al. Intravenous magnesium sulphate for aneurysmal subarachnoid hemorrhage (IMASH): A randomized, double-blinded, placebo-controlled, multicenter phase III trial. Stroke 2010;41:921-6.

32. Wong GK, Chan MT, Boet R, Poon WS, Gin T. Intravenous magnesium sulfate after aneurysmal subarachnoid hemorrhage: A prospective randomized pilot study. J Neurosurg Anesthesiol 2006;18:142-8.

33. Mees SM, Algra A, Vandertop WP, van Kooten F, Kuijsten HA, Boiten J, et al. Magnesium for aneurysmal subarachnoid haemorrhage (MASH-2): A randomised placebo-controlled trial. Lancet 2012;380:44-9.

34. Macdonald RL, Higashida RT, Keller E, Mayer SA, Molyneux A, Raabe A, et al. Clazosentan, an endothelin receptor antagonist, in patients with aneurysmal subarachnoid haemorrhage undergoing surgical clipping: A randomised, double-blind, placebo-controlled phase 3 trial (CONSCIOUS-2). Lancet Neurol 2011;10:618-25.

35. Macdonald RL, Kassell NF, Mayer S, Ruefenacht D, 
Schmiedek P, Weidauer S, et al. Clazosentan to overcome neurological ischemia and infarction occurring after subarachnoid hemorrhage (CONSCIOUS-1): Randomized, double-blind, placebo-controlled phase 2 dose-finding trial. Stroke 2008;39:3015-21.

36. Macdonald RL, Higashida RT, Keller E, Mayer SA, Molyneux A,
Raabe A, et al. Randomized trial of clazosentan in patients with aneurysmal subarachnoid hemorrhage undergoing endovascular coiling. Stroke 2012;43:1463-9.

37. Devereaux PJ, Chan MT, Eisenach J, Schricker T, Sessler DI. The need for large clinical studies in perioperative medicine. Anesthesiology 2012;116:1169-75. 